\title{
Processos de Rurbanização Contemporânea - o transporte de tração animal em cidades de médio porte: um estudo de caso
}

\author{
Contemporary Rurbanization Processes - the animal traction transport in \\ medium-sized cities: a case study \\ Processus de Rurbanisation Contemporaines - le transport à traction animale \\ dans les villes de taille moyenne: une étude de cás \\ Procesos de Rurbanización Contemporánea-el transporte de tracción animal \\ en las ciudades de tamaño medio: un estudio de caso \\ José Marcos Froehlich ${ }^{1}$ \\ Rosa Cristina Monteiro² \\ Ronald Clay dos Santos Ericeira ${ }^{2}$
}

Recebido em 23/03/2016; revisado e aprovado em 15/04/2017; aceito em 15/04/2017

DOI: http://dx.doi.org/10.20435/inter.v18i2.1536

\begin{abstract}
Resumo: O artigo se fundamenta na noção de rurbanidade como operador analítico para situações socioambientais híbridas, que se articulam na tensão entre o meio rural tradicional e a urbanização acelerada dos projetos desenvolvimentistas. A investigação aborda a permanência do uso de transporte de tração animal em contextos de franca urbanização, como processo representativo da condição rurbana. Os resultados demonstram que os carroceiros nem sempre têm a visibilidade social correspondente à sua importância sociocultural.
\end{abstract}

Palavras-chave: ruralidade; identidade cultural; carroceiros.

Abstract: The article is based on the notion of rurbanity as an analytical operator for socio-environmental hybrid situations, which are articulated in the tension between the traditional rural environment and the accelerated urbanization of developmental projects. The research addresses the permanence of the use of animal traction transport in contexts of urbanization, as a representative process of the rurban condition. The results show that carters do not always have the social visibility corresponding to their sociocultural importance.

Key words: rurality; cultural identity; carters.

Résumé: Cet article est basé sur la notion de rurbanité comme un opérateur d'analyse pour les situations environnementales hybrides qui sont articulés dans la tension entre le milieu rural traditionnel et l'urbanisation rapide des projets de développement. La recherche se concentre sur la permanence de l'utilisation des transports à traction animale dans les contextes urbains comme un processus représentatif de l'état de rurbain. Les résultats montrent que les charretiers ne disposent pas toujours la visibilité sociale correspondant à son importance socio-culturelle.

Mots-clés: ruralité; identité culturelle; charretiers.

Resumen: El artículo se basa en la noción de rurbanidade como operador de analisis de situaciones socioambientales híbridas que se articulan en la tensión entre el mundo rural tradicional y la rápida urbanización de los proyectos desarrollistas. La investigación se ocupa de la permanencia del uso de transporte de tracción animal en contextos urbanos como un proceso representativo de la condición rurbana. Los resultados muestran que los carreteros no siempre tienen la visibilidad social que corresponde a su importancia socio-cultural.

Palabras clave: ruralidad; identidad cultural; carreteros.

\footnotetext{
${ }^{1}$ Universidade Federal de Santa Maria, Santa Maria, Rio Grande do Sul, Brasil.

${ }^{2}$ Universidade Federal Rural do Rio de Janeiro, Rio de Janeiro, Brasil.
} 


\section{INTRODUÇÃO}

Este artigo tem como fundamento o interesse em investigar o fenômeno psicossocial da rurbanidade, pesquisando a utilização das carroças em meio social recentemente urbanizado, ao mesmo tempo em que apresenta uma reflexão sobre a problemática identitária que envolve os carroceiros que circulam no município de Seropédica, no Rio de Janeiro, Brasil. Com efeito, trata-se do recorte de uma pesquisa que utilizou métodos quantitativos e qualitativos com parte da população moradora e frequentadora do município, que entra em contato diretamente com as carroças e os carroceiros, e do relato de um estudo etnográfico/descritivo com os próprios carroceiros e suas famílias.

Cabe destacar que partilhamos a crítica de Magnani (2002) sobre a forma rotineira de se fazer os estudos nas cidades, posto que enfatizam os aspectos macrossociológicos desagregadores dos espaços urbanos (deficiência da rede de transportes, falta de moradia, saneamento básico precário etc), sem promoverem, entretanto, a visibilidade dos atores sociais que circulam nas e pelas cidades. Pautando-se em uma perspectiva etnográfica, Magnani (2002) sugere uma postura investigativa de identificação das regularidades dos estilos de vida e dos deslocamentos dos diferentes grupos sociais nos espaços das cidades.

Partidários dessa visão, no primeiro momento deste artigo, produzimos uma sucinta revisão bibliográfica de referenciais analíticos que fundamentam a discussão sobre a urbanização/ rurbanização dos espaços humanos. No segundo momento, trazemos à baila a análise dos resultados de nossa investigação. Tratando-se de uma pesquisa de cunho etnográfico, enfatizamos delinear as formas pelas quais nossos interlocutores - os carroceiros- transitam pela cidade de Seropédica, como usufruem seus serviços, utilizam seus equipamentos urbanos/rurais, e estabelecem encontros e trocas com os demais atores sociais da cidade, construindo um modo de ser e viver próprio, que pode ser apreendido em sua singularidade e revalorizado no domínio das políticas públicas que levem em conta a noção de rurbanização.

\section{A URBANIZAÇÃO DOS ESPAÇOS}

O pensamento político e as práticas de gestão e planificação social ocidental foram dominados, deste a revolução industrial inglesa até o final do século XX, pela ideia de urbanização, entendida como a concentração, em certos espaços, de recursos técnico-tecnológicos gerados e geridos segundo a expansão da racionalidade tecnocientífica que marcou o período (SANTOS, 1996). No limiar da passagem entre o século XIX e o século XX, a ideia de urbanização era legitimada pela perspectiva de eficácia e operacionalidade compatível com a transformação da sociedade no sentido de sua industrialização.

Em certos referenciais analíticos, as cidades modernas são a própria expressão do capital em expansão, contrastando com as cidades antigas, que sustentavam a relação dialética com o campo. Assim, para Lefebvre (1999), as grandes cidades industriais, comerciais e políticas protagonizam o cenário de passagem para o modo de produção capitalista, no arco econômico e social.

Em outra interpretação, é o desdobramento da técnica que se torna sujeito do processo histórico, posto que, com a industrialização, os objetos e sistemas técnicos adquirem uma força incontornável de modelagem cultural e social:

As épocas se distinguem pelas formas de fazer, isto é, pelas técnicas. Os sistemas técnicos envolvem formas de produzir energia, bens e serviços, formas de relacionar os homens

INTERAÇÕES, Campo Grande, MS, v. 18, n. 2, p. 157-169, abr./jun. 2017. 
entre eles, formas de informação, formas de discurso e interlocução... O período técnico vê a emergência do espaço mecanizado. Os objetos que formam o meio não são, apenas, objetos culturais; eles são culturais e técnicos, ao mesmo tempo. Quanto ao espaço, o componente material é crescentemente formado do 'natural' ao 'artificial'. Mas o número e a qualidade de artefatos variam. As áreas, os espaços, as regiões, os países passam a se distinguir em função da extensão e da densidade da substituição, neles, dos objetos naturais e dos objetos culturais, por objetos técnicos. (SANTOS, 1996, p. 158).

O espaço urbano aparece, na modernidade, como o espaço por excelência, destino de todas as construções humanas a acompanhar a marcha das conquistas civilizatórias. Ser urbano, conforme nos indicam os dicionários da língua portuguesa, é não somente pertencer à cidade, mas é igualmente ser cortês, afável, civilizado. Urbanizar é também polir, civilizar (CRUZ SOUZA; MONTEIRO, 2000).

A expansão da urbanização no Brasil ocorreu em um ritmo que tendeu a acelerar-se durante todo o decorrer do século XX, com especial ênfase nas décadas 1950/1960. Esse intervalo corresponde aos esforços de redesenho das sociedades e coletividades destruídas por duas Grandes Guerras Mundiais.

No território brasileiro, é possível captar-se a existência de um movimento (quase) contínuo que se iniciou com a introdução dos transportes ferroviários (a partir da metade do século XIX) e culminou na década de 70 do século XX, quando se passou a falar profusamente na revolução modernizante do rural e da agricultura, com o incremento exponencial da motomecanização e quimificação na produção agrícola, e com a alteração do regime de identidades socioculturais, que, em período anterior, distinguia o agricultor do trabalhador industrial.

Apesar de uma mentalidade que tendia à totalização, alguns espaços geográficos permaneceram à sombra dos investimentos técnicos/tecnológicos e, do ponto de vista social, passaram a caracterizar um resíduo de ruralidade, considerado até recentemente como falha no processo de desenvolvimento: atraso a ser superado. Quando colocado em perspectiva sob a ótica da urbanização, os espaços rurais também foram algumas vezes considerados complementares aos espaços urbanos, como intervalo para uma vida em ritmo lento, em contraste com a aceleração exigida pela atividade industrial: espaço exótico, pitoresco, disponível para o desfrute de alguns poucos privilegiados. Neste último caso, os espaços foram tratados como áreas de preservação e deram origem a reservas e parques (MONTEIRO, 2009), ações emblemáticas de um contexto social eivado de paradoxos e antinomias sobre a noção de natureza (FROEHLICH; BRAIDA, 2010).

A realidade considerada rural sofreu uma clivagem que distinguia um rural moderno/ modernizado, equipado e rico, e um rural tradicional, conservador e pobre. Após algumas décadas de predomínio dessa concepção, o modelo entrou em crise e, já na entrada do século $X X I$, as ciências sociais tornam-se prolíficas nos debates a respeito da ressignificação das tensões campo-cidade ${ }^{3}$, promovendo a emergência de certos conceitos e a retomada de outros. Nesse contexto aparece a noção de "novo rural", como estratégia de reflexão e ação que valoriza os aspectos políticos e culturais dos planos de desenvolvimento, destronando o valor exclusivo da economia (MONTEIRO, 2009). Como consequência dos novos significados atribuídos, tornou-se possível conceber "a noção de ruralidade como um conjunto de categorias referidas a um universo simbólico ou visão de mundo que orienta práticas sociais distintas em ambientes culturais heterogêneos" (FROEHLICH, 2002, p. 123).

\footnotetext{
${ }^{3}$ É possível acompanhar esta discussão em Diesel e Froehlich (2009).
} 
Além da ressignificação mesma do rural, é de particular interesse em nossa pesquisa a retomada da noção de "rurbano", significando a formação de uma configuração híbrida com respeito às práticas ambientais e sociais. A sociologia brasileira já contava com esse conceito desde 1982, quando Gilberto Freyre propugnou a adoção de modelos de desenvolvimento que superassem, por um lado, o excesso patológico de urbanização e, por outro lado, a retomada romântica de arcaísmos rurais. Duas décadas após as sinalizações de Gilberto Freyre, a sociologia enfim retomou a proposta de rurbanização para explicar a interpenetração dialética dos dois meios e estabelecer novas pautas de desenvolvimento, especialmente nos territórios situados nas consideradas periferias mundiais (FROEHLICH, 2000).

Também um grupo de pesquisadores argentinos, ligados à Universidade Nacional de Rio Cuarto (Argentina), trabalhou intensivamente nas últimas décadas com a hipótese de que certas transformações que preocupavam a sociedade e centravam-se fundamentalmente em ambientes mega-urbanos, e na probabilidade de extinção definitiva do meio rural, deveriam ser revistas. Para os pesquisadores desse grupo, o ambiente rural se manifesta em um conjunto de processos psicossociais que não podem interpretar-se unicamente desde uma prefiguração urbana. Entendem eles que as respostas à pobreza, às migrações forçadas, à marginalização, exigem contemplar o rural como dimensão que ajuda a compreender melhor o que sucede nos centros urbanos (CIMADEVILLA, 2002). Assim, os autores consideram que a presença de modos de produzir sociais e culturais típicos da vida rural, em situações de intensa urbanização, consistem em rurbanidade.

A partir dessa hipótese, Cimadevilla e Carniglia (2010) localizam, descrevem e inserem definitivamente na agenda das pesquisas sociais e das práticas de planejamento ambiental o fenômeno que consiste na persistência do transporte de tração animal (no Brasil, as chamadas "carroças") em cidades de pequeno, médio e grande porte. Em suas observações, constataram que um número crescente de famílias resolve sua existência diária através de atividades que implicam o transporte por carroças.

Esses agentes, individuais e coletivos, utilizam carros puxados a cavalos para realizar distintas atividades, encontrando nessa estratégia de sobrevivência uma maneira de superar a vida em contexto de exclusão social violenta, visível e recorrente. Entre suas atividades, destacam-se a coleta informal de lixo; a extração e venda de matérias básicas, como areia de rio, saibro, pedras; e a venda ambulante de frutas, verduras e todo tipo de material doméstico. Também utilizam o sistema de carroça, ou charrete, para transportar grupos e famílias para atividades recreativas.

O fenômeno não está restrito à localidade que os autores descreveram e analisaram. Uma vez instrumentados por essas lentes de observação e análise, não deixamos de ver por todos os lados, em especial nas cidades onde a urbanização se manifesta de forma acelerada e sem planejamento, a recorrência dessa prática econômica, social e cultural.

A conclusão a que chegam os autores (CIMADEVILLA; CARNIGLIA, 2010) é por nós inteiramente partilhada como conclusão de pesquisa etnográfica, e consiste no problema básico do projeto de pesquisa que conduzimos: o fenômeno dos carroceiros na cidade chama a atenção pela visibilidade/invisibilidade que tem na sociedade e pelas leituras que provoca nos demais atores sociais citadinos. Ele é particularmente importante pelo que implica para seus protagonistas, enquanto modo de vida e subsistência, e pelo conjunto amplo de significados contidos em seus ambientes e sistemas de objetos: formas culturais inerentes e formas culturais expressas (CIMADEVILLA; CARNIGLIA, 2010). 
Em Seropédica, palco de nossa pesquisa etnográfica, identificamos a presença de um expressivo número de carroças que circulam cotidianamente nos perímetros considerados urbanos da cidade, trafegando à margem da principal via expressa asfaltada, nos interstícios da malha viária urbana, no campus da Universidade Federal Rural do Rio de Janeiro (UFRRJ). A partir de observações e de registros realizados durante um ano, em intervalos de aproximadamente uma semana, estimamos em mais de sessenta o número de carroças em uso na cidade. Não incluímos nessa estimativa as carroças que estão em uso exclusivamente no meio rural. A circulação dos carroceiros em e por Seropédica nos impôs os seguintes questionamentos: qual o grau de visibilidade/invisibilidade dos carroceiros entre moradores do referido município? Qual a importância que essa população Ihes atribui? É possível esboçar um modo de vida ou visão de mundo próprios desse grupo social? Podemos utilizar a noção de rurbano para caracterizar esses atores sociais? Como considerar os interesses desse grupo nos planos de desenvolvimento social?

\section{SEROPÉDICA E SEUS CARROCEIROS: PROCEDIMENTOS DE COLETA DE DADOS}

Antes de detalhar a metodologia utilizada nesta pesquisa, convém uma breve explanação sobre o processo de urbanização de Seropédica. A cidade, até 1930, possuía uma configuração eminentemente rural. No entanto, em meados daquela década, começaram em Seropédica as obras do Centro Nacional de Estudos e Pesquisas Agronômicas, onde atualmente funciona a Universidade Federal Rural do Rio de Janeiro (UFRRJ). Esta, em 1948, teve seu campus transferido para as margens da antiga rodovia Rio-São Paulo, hoje BR-465. Os movimentos populacionais em torno da Universidade promoveram a chegada de equipamentos urbanos que alteraram uma parte da paisagem do município. Apesar da presença da UFRRJ e de outros institutos federais de pesquisa e extensão rural, no território de Seropédica a ocupação socioambiental dessas instituições públicas contrasta com o modo mais frequente de habitação no incipiente contexto urbano, caracterizado por habitações precárias, com falta de infraestrutura e de serviços básicos. Em 1995, Seropédica tornou-se emancipada, constituindo-se em municipalidade. Com a emancipação, a cidade teve sua economia movimentada e ganhou obras de infraestrutura, que permitiram definir um perímetro urbano de grande densidade. Este vem se ampliando pela própria expansão da Universidade Rural e suas áreas de influência, e, mais recentemente, pela construção de uma obra de grande impacto socioambiental: a construção de um Arco Metropolitano, que faz parte do Plano de Aceleração do Crescimento (PAC) dos governos federal brasileiro e estadual do Rio de Janeiro (ERICEIRA; et al., 2013).

Nessa realidade ambiental de Seropédica, com um quadro completamente diverso do seu passado rural longínquo, mas que ainda apresenta uma imperfeita urbanização, foi onde coletamos dados sobre os carroceiros citadinos. Sendo uma investigação envolvendo preceitos da etnografia, é mister apresentar as condições de coleta de dados (OLIVEIRA, 2000; VIEGAS, 2007).

De antemão esclarecemos que a pesquisa supracitada já dura três anos. Cada ano correspondeu a uma etapa da coleta e da sistematização dos dados. No primeiro ano, realizamos etnografia durante dias e horários alternados da semana e do fim de semana, fazendo uma estimativa do alcance do fenômeno observado e de sua recorrência. Nesse período, constatamos haver um expressivo número de carroças circulando no trânsito da cidade. Nesse transcurso, realizamos ainda entrevistas curtas com os carroceiros, de modo aleatório, segundo a situação em que se os encontravam (em trânsito ou estacionados). Paralelamente, alunos de iniciação 
científica aplicavam questionários ${ }^{4}$ com a população local. Essa coleta de dados foi dividida em dois momentos: inicialmente o instrumento foi aplicado a 94 pessoas, de uma amostra casual simples, extraída da totalidade de pessoas que circulavam pelas ruas de maior movimento de transeuntes na cidade. Desse total, 66 sujeitos moram no município e 28 sujeitos o frequentam com regularidade, em atividades de estudo e trabalho. No segundo momento, o mesmo questionário foi aplicado a 121 estudantes do ensino médio de duas escolas públicas do município: 60 estudantes de uma escola de formação técnica e 61 estudantes de uma escola de ensino regular; entre os estudantes, 35 moram em Seropédica e 86 a frequentam regularmente.

No segundo ano da pesquisa, sistematizamos os dados quantitativos da pesquisa e passamos a frequentar as propriedades de dois carroceiros, levantando dados a respeito de suas histórias de vida e suas condições atuais de sobrevivência. Depois de aproximadamente três meses de tais aproximações, passamos a contar com dois etnofotógrafos, formados na Escola Imagens do Povo, que acompanharam os carroceiros em duas jornadas diárias cada um. As jornadas diárias consistiam em oito horas de acompanhamento com a gravação de entrevistas e realização de fotos. No terceiro ano da pesquisa, foram entrevistados outros carroceiros, com entrevistas abertas conduzidas por uma bolsista de iniciação científica, graduanda de psicologia. As interações nesse caso ocorreram em pontos de estacionamento de carroças, contando com a disponibilidade dos interlocutores.

\section{ANÁLISE E DISCUSSÃO DOS RESULTADOS}

Para efeito de exposição argumentativa, dividimos a apresentação dos dados da pesquisa em duas partes: uma referente à análise dos questionários e outra concernente à etnografia e à história de vida dos carroceiros.

\subsection{Avaliações das carroças e carroceiros pela população Seropedicense}

Na totalidade dos questionários aplicados, a amostra revelou que as carroças apenas são mencionadas como meio de transporte em $20 \%$ do total das respostas. No que tange à utilização de carroças, o percentual de respostas afirmativas foi de $23 \%$. Entre os que utilizaram as carroças, os usos mais frequentes foram: locomoção - 50\% (deslocamento pessoal de um ponto a outro); transporte de carga - 20\% (incluindo mudança); lazer - 30\%. Sobre as justificativas para ter utilizado a carroça, a resposta mais frequente foi a de que a carroça se apresentou, em certo momento, como a única opção viável. Apenas uma pessoa respondeu não ter ficado satisfeita com a utilização da carroça, e duas informaram que não utilizariam novamente.

A importância histórica das carroças em Seropédica foi destacada na resposta de uma mulher, de 41 anos, que lembrou e narrou o uso frequente que fazia delas quando devia buscar água na fonte durante a infância e a adolescência: "para carregar a água, a gente levava os galões vazios na carroça, enchia com água e trazia pra casa. Era uma fila esperando. Não tinha outro jeito, e a gente sabia conduzir muito bem".

\footnotetext{
${ }^{4}$ Os questionários tinham as seguintes questões fechadas: quais os meios de transporte que você identifica no município?; você já utilizou a carroça como meio de transporte?; se a resposta foi afirmativa, para qual finalidade?; por que optou pela carroça nesta ocasião?; ficou satisfeito com o serviço?; usaria novamente?. Uma questão aberta encerrava o instrumento: você gostaria de acrescentar alguma consideração sobre o uso de carroças em Seropédica, ou sobre os carroceiros?
} 
Por outro lado, foi constatada a recorrência de um sentimento de vergonha ao usar a carroça. Um homem de 60 anos de idade, por exemplo, que usou o transporte para carregar mudança, declarou sentir-se bem envergonhado quando viu seus móveis e utensílios expostos e que em parte se arrependeu da economia feita ao escolher a carroça para realizar sua mudança. Do mesmo modo, ainda que avaliasse a locomoção por meio de carroça algo divertido, uma mulher jovem, de cerca de 20 anos de idade, também se declarou envergonhada ao ser vista pelos amigos andando de carroça. Eis seu comentário:

Sentia vergonha, sei lá, as pessoas olharem e rirem. Se eu visse alguém que fosse conhecido, eu ria. É muito engraçado. Eu acho que as carroças bonitinhas, enfeitadas, que eu vejo em filme, são muito bonitinhas. O que eu vejo aqui são carroças muito feias, os bichinhos muito maltratados. Chega até dar dó dos bichinhos [...].

Outrossim, uma mulher na faixa dos 25 aos 35 anos, professora primária, moradora do município, além de não ter mencionado a carroça como meio de transporte, expressou uma visão pejorativa sobre os carroceiros, a saber:

São pessoas do interior tradicional, que não têm contato com carro. Sua principal atividade econômica é a agricultura. Se vestem e falam diferente. Não parecem tristes. Poderiam ter um olhar mais crítico sobre o lugar onde moram, porque é tudo precário, buracos, falta de rua. Mas eles parecem que não se incomodam com isso não. Eles estão bem assim.

Em contrapartida, um entrevistado jovem, que trabalha de motoboy e faz ponto em frente aos dois maiores supermercados da cidade, não hesitou em mencionar as carroças como meio de transporte muito útil à população, discorrendo sobre o tema em tom incisivo e eloquente: "uma carroça nesse tipo de movimento é muito perigoso, o cavalo pode ficar doido, machucar alguém", para logo prosseguir em movimento solidário - "tem que ver tudo isso aí, buraco, rua não asfaltada, o município tá largado, tem que organizar, tem que dar um jeito pra todo mundo", e avançou no encaminhamento - "carroça vantagem tem, pra carregar cimento, tijolo, eucalipto, televisão, não precisa usar o carro, e pra isso a moto não dá, e a carroça não polui não, né? Nem gasta gasolina, é mais barato, e não estraga, e os caras precisam, né?".

As respostas obtidas nos questionários evidenciam que a opinião sobre os carroceiros são difusas e parciais. São percepções quase sempre fundamentadas em situações distantes da prática real atual dos nossos interlocutores.

\subsection{Vida de carroceiro entre o rural e o urbano: trajetórias de vida}

$\mathrm{Na}$ etnografia realizada, distinguimos três diferentes condições de ser carroceiro em Seropédica, quais sejam: há carroceiros que transitam casualmente, com atividades diferentes e preferencialmente em dias de chuva, quando é difícil o deslocamento a pé ou com bicicleta devido aos buracos e às poças de água; há carroceiros prestando serviços a proprietários rurais, que são os donos das carroças; e existem carroceiros usando suas próprias carroças em atividades sistemáticas, transitando entre o centro comercial, administrativo e financeiro de Seropédica (zona urbana) e suas propriedades rurais. Apesar dessas distintas modalidades, as entrevistas feitas com carroceiros e suas famílias nos permitiram constatar a existência de práticas psicossociais correspondentes à permanência das características rurais do município e às dificuldades de adaptação dos carroceiros ao contexto de urbanização da cidade. Para dar visibilidade aos principais problemas e às alternativas encontradas ou apontadas pelos carroceiros, apresentamos

INTERAÇÕES, Campo Grande, MS, v. 18, n. 2, p. 157-169, abr./jun. 2017. 
a seguir narrativas sintéticas feitas a partir da trajetória de vida, com ênfase nos aspectos laborais, dos nossos interlocutores ${ }^{5}$.

\subsubsection{Senhor Marcos}

Senhor Marcos tem 74 anos e se apresentou, imediatamente, como "carroceiro". De fato, sua presença conduzindo a carroça é uma constante nas ruas principais do município. Durante todo o tempo da pesquisa, não deixamos de vê-lo nem um só dia quando fomos a campo fazer observações. Seu Marcos declara que seus primeiros trabalhos foram na enxada "puxando cobra pra cima do pé" (sic). O primeiro emprego de que recorda foi na granja de um espanhol, em Seropédica. Sua experiência na granja, que criava galinhas de raça, foi de um trabalho com muita exploração e péssimo tratamento dispensado aos empregados. Com um ano e três meses de trabalho na granja, Seu Marcos se revoltou e saiu. Em seguida trabalhou na Universidade Rural. Daí também evoca lembranças de atividades duras, com muito esforço físico, péssimas condições de trabalho e remuneração insuficiente. Naquela época, plantava-se milho, feijão e arroz na UFRRJ, e essa produção, além de abastecer o restaurante da universidade, era compartilhada com os moradores do entorno e os trabalhadores locais.

A primeira carroça de Seu Marcos foi adquirida em uma fábrica em Nova Iguaçu, servindo- Ihe para entregar leite. Hoje a carroça é utilizada para recolher a lavagem que alimenta os porcos de sua própria criação. Eventualmente faz frete. Quando interpelado sobre a profissão de carroceiro, ele não sabe responder com desenvoltura. Quanto à dificuldade de lidar com a carroça, ele considera importante saber lidar com o animal: "é igual carro na estrada". Nesse ponto, o Senhor Marcos faz questão de contar que sempre revezava os animais para não causar dano a nenhum deles. Por fim, ele avalia que atualmente a pista está muito mais perigosa para as carroças, com muitos caminhões e carretas.

\subsubsection{Senhor Rubens}

Rubens e Joana formam um casal e têm 3 filhos. Há mais de 15 anos, Rubens, 64 anos, exerce o oficio de construtor rural: faz curral, monta balanças, constrói embarcador de gado e fabrica carroças. O casal orgulha-se em dizer que boa parte das carroças que trafegam no município são construções de Seu Rubens, com a participação da família. Além do veiculo propriamente dito, o engenho do casal consiste na preparação dos acessórios, como as rédeas e os cabrestos. Durante algum tempo, toda a família trabalhou no mesmo oficio. Joana, que tem hoje 56 anos, não encontra mais condição de sobrevivência na atividade rural e agora se dedica ao trabalho doméstico, fazendo faxina e lavando roupas para outras pessoas. Os filhos também já não trabalham mais com o pai.

Rubens nasceu em uma fazenda no próprio município, onde aprendeu a fazer cercas. Ele é fortemente identificado com o meio rural e gosta de andar a cavalo. Na medida em que as atividades rurais de Seropédica declinam, ele busca trabalho em fazendas do interior. A família mantém um arquivo fotográfico com imagens das várias carroças que foram construídas em seu terreno.

\footnotetext{
${ }^{5}$ Seguindo normas da pesquisa, foram utilizados nomes fictícios para ilustrar a história de vida dos carroceiros de Seropédica.
} 
Quando saiu de casa, há dois anos, para trabalhar na construção rural em uma fazenda do município vizinho, Seu Rubens deixou em seu quintal uma carroça recém-adquirida, que tinha (ou tem) a intenção de preparar para o seu uso. Com as carroças, sempre que possível, o senhor Rubens faz mudança e transporta material de construção.

Uma das maiores dificuldades para seu Rubens agora é a criação do animal para a carroça. Com a expansão da família, o lote de terra foi fracionado e hoje já não tem mais espaço para a criação. O quão recente é o processo de urbanização de Seropédica pode ser avaliado pelas lembranças de Joana, de ter vivido muitos anos sem energia elétrica, usando ferro de passar a carvão, lamparina, cozinhando em fogão de lenha. "Há 38 anos atrás isso aqui era só campo, não tinha loteamento, não tinha nada. A água era puxada na caçamba e a roupa lavada na tina. A tina também servia para o banho". Joana relata com ressentimento o alcoolismo do marido, mas o justifica dizendo que é "estresse do serviço: serviço pesado e desgastante".

\subsubsection{Senhor José}

Seu José Mateus, ou apenas Zé, como gosta de ser chamado, é um mineiro de 62 anos que há 50 anos vive no estado do Rio de Janeiro e há 25 anos vive em Seropédica. Embora se defina como caseiro, sua principal atividade consiste em fazer trabalhos com a carroça: seja para buscar as sobras de comida do Restaurante Universitário da UFRRJ para levar para os porcos do sítio onde vive; seja para carregar os entulhos para fazer a limpeza do local; seja para levar o plantio e colheita que ele mesmo produz; ou ainda para simplesmente se locomover na e pela cidade. Seu maior orgulho é o fato de todos os quatro filhos saberem ler e escrever e terem um emprego considerado bom. Seus filhos são caixa de supermercado, obreiro, vendedor e auxiliar de serviços gerais. Emprego bom, para Zé, é ter carteira assinada. Algo que ele nunca teve, mas sabe a importância que é: "a gente fica mais garantido se acontecer alguma coisa, né?" (sic).

Seu José não se lembra com quantos anos começou a trabalhar, mas sabe que era criança. "A foice era maior do que eu. Eu nem conseguia carregar direito". Ele se lembra que ia junto com o pai e os irmãos homens para roça, capinar, plantar e colher galhos para o fogão a lenha da casa onde moravam, enquanto a mãe e as irmãs iam para o rio lavar roupas. A mãe lavava essas roupas para terceiros em troca de dinheiro. Seu José também se lembra de que ainda criança veio com a família para o Rio de Janeiro, e à medida que crescia, pegava trabalhos cada vez mais pesados: foi capinador, engraxate, servente de pedreiro, carregador de cimento, descarregador de materiais de obra. Não se lembra de ter estudado depois que saiu de Minas, mas sabe que terminou a 1a série (alfabetização), orgulhando-se de saber escrever o próprio nome.

Ao conseguir o atual emprego, há seis anos, ficou encantado por ganhar uma casa. Sendo viúvo, faz questão de frisar que namora bastante, e que os fins de semana são reservados para passar com a noiva, com quem se relaciona há cinco anos e com quem ainda só não se casou pelo emprego dela, o de doméstica em uma casa na cidade do Rio de Janeiro, onde precisa estar de segunda a sexta durante todo o dia e toda a noite. Seu Zé também está satisfeito com a vida familiar, diz ter bastante contato com os filhos, todos morando próximo e conseguindo ter encontros frequentes para manter a proximidade.

Quanto ao seu emprego, ele não tem queixas. Embora tenha aprendido a puxar a carroça por necessidade para o atual trabalho, diz que não teve dificuldade por ser acostumado a lidar com os animais já há bastante tempo. O trabalho pode até ser pesado, mas Seu José Mateus

INTERAÇÕES, Campo Grande, MS, v. 18, n. 2, p. 157-169, abr./jun. 2017. 
aprendeu a trabalhar pesadamente ainda pequeno, e a vida o fez se acostumar a isso. E, por falar em vida, ele só tem uma coisa a dizer sobre a sua: "Ela tá boa...".

\subsubsection{Senhor Manoel}

O Sr. Manoel, analfabeto, é um homem negro, muito magro, não possui os principais dentes e quando foi abordado e perguntado se poderia responder a algumas questões a fim de ajudar na pesquisa, às sete horas da manhã de uma quinta-feira, se encontrava bêbado. Aparenta muito mais do que os quarenta e quatro anos que afirma ter. Sua carroça, a poucos metros de distância de onde se encontrava, estava aguardando por ele junto a um burro aparentemente tão mal cuidado quanto o dono. Apesar do quadro de embriaguez, ele foi extremamente solícito ao aceitar conversar e contar um pouco sobre sua história de vida.

Natural da cidade de Niterói, no estado do Rio de Janeiro, Senhor Manoel vive em Seropédica há mais ou menos 15 anos, quando decidiu vir para o interior a fim de uma vida mais simples e menos despesas. Trabalhava até então como ajudante de serviços gerais, mas, desde que se mudou, comprou uma carroça a fim de ser autônomo e assim tentar prosperar. Optou pela carroça pelo baixo custo, deduzindo que tudo que um burrico precisaria seria de um pasto. Trabalha atualmente com a carroça fazendo fretes, carregando entulhos, fazendo limpezas de loteamentos e descarregando materiais em geral.

Há cerca de oito anos, Seu Manoel ficou viúvo. Vive com os dois filhos, e estes possuem 15 e 12 anos e estão, respectivamente, na 5 a e 2 a série do ensino primário. Ele vê o estudo dos filhos como algo positivo, não parecendo ter noção da dimensão e atraso escolar destes. Os meninos, definidos pelo pai como garotos bons e tranquilos, não usam a carroça por terem vergonha, mas Seu Manoel não se abala, diz que está satisfeito com o atual trabalho de carroceiro, afinal dá para tirar o sustento dele e das crianças.

\section{CONSIDERAÇÕES REFLEXIVAS, À GUISA DE CONCLUSÃO}

Retomando a discussão de Magnani (2002) sobre a visibilidade/invisibilidade dos atores sociais nas cidades, os dados quantitativos nos permitem concluir que as carroças não são concebidas como meio de transporte do município, em flagrante contraste com a evidência etnográfica de que são, muitas vezes, utilizadas para fins de transporte, e que elas correspondem às expectativas, quando são mencionadas.

Na perspectiva qualitativa, alguns dados merecem destaque, quais sejam: 1) a menção de um sentimento de vergonha quando se é flagrado utilizando uma carroça como passageiro, evidencia uma atribuição negativa a esse meio de transporte; 2) O reconhecimento de que os carroceiros são trabalhadores contrasta com certa posição emergente em movimentos ativistas na proteção aos animais, que atribui aos carroceiros alguma espécie de "maldade atávica", que os faria usar os animais sem escrúpulos.

Por seu turno, o conjunto das narrativas supracitadas evidencia aquela crítica ao modelo de desenvolvimento urbano-industrial, já amplamente avaliado e insistentemente recorrente na literatura. O grupo social vivenciou as tensões de um processo baseado na exaltação urbano-industrial, apresentadas nas considerações de Gilberto Freyre:

[...] progressismos [...] introduzidos em espaços rurais com prejuízos para suas gentes e seus moradores mais valorosos. Poluições. Degradações de recursos naturais. Desequilíbrios 
ecológicos: isto é, desequilíbrios nas relações de ruralitas com seus ambientes ou com suas ecologias. [...] Ao que se acrescente o que vêm sendo desequilíbrios, através de explorações por poderes econômicos, do braço trabalhador. Restrições a oportunidades de trabalho remunerador para ruralitas jovens, causando emigrações consideráveis [...]. (FREYRE, 1982, p. 24-25).

Ao tentar resolver a vida equilibrando-se entre as duas polaridades: urbano e rural, os carroceiros de Seropédica passam a simbolizar a condição rurbana, como um estado intermediário que cria um tipo psicossocial misto, definindo espaços híbridos.

Nesses termos, o trânsito das carroças em Seropédica, em ritmo lento, frente à velocidade dos carros, ônibus, caminhões e motos, nos remete à leitura de Milton Santos (2002) sobre o "tempo", quando analisa as cidades:

A cidade é o palco de atores os mais diversos: homens, firmas, instituições, que nela trabalham conjuntamente. Alguns movimentam-se segundo tempos rápidos, outros, segundo tempos lentos, de tal maneira que a materialidade que possa parecer como tendo uma única indicação, na realidade não a tem, porque essa materialidade é atravessada por atores, por essa gente, segundo os tempos, que são lentos ou rápidos. Tempo rápido é o tempo das firmas, dos indivíduos, das instituições hegemônicas e tempo lento é o tempo das instituições, das firmas e dos homens hegemonizados. A economia pobre trabalha nas áreas onde as velocidades são lentas. Quem necessita de velocidades rápidas é a economia hegemônica, são as firmas hegemônicas. (SANTOS, 2002, p. 2).

Parafraseando Oliveira (apud CABANES; GEORGES, 2011), o grupo social que focalizamos faz parte daqueles transformados em insetos na ordem capitalista que se expande com voracidade no município de Seropédica, em função das atuais políticas de aceleração do crescimento. Efetivamente, toda a dinâmica recente ligada às alterações do mundo do trabalho está em jogo, com a incontestável conclusão de que o trabalhador está ficando sem saída:

[...] a banalização da situação atual deve-se a esse realismo imposto por informações econômicas que visam obscurecer deliberadamente os saberes, às verdades ideológicas passageiras, alimentando e cultivando práticas de destruição do outro para que seja possível tomar seu lugar. (CABANES; GEORGES, 2011, p. 11).

Nesse sentido, as atuais análises psicossociais revelam um dado incontornável:

Essa contradição interna do sistema capitalista associa uma estratégia de rigorosa individualização no trabalho a uma fragilização desse mesmo trabalhador por políticas de precarização do emprego e do controle da atividade produtiva. Ela não oferece alternativa no plano da revalorização do trabalho. (CABANES; GEORGES, 2011, p. 12).

Entendemos que o grupo de trabalhadores aqui identificados, cuja prática é histórica e quase se oferece como resistência à implacável violência dos processos de expansão e eliminação dos desiguais, pode ser revalorizado na perspectiva de um outro programa social.

Latouche (2009) aponta a necessidade imperiosa de revalorizar o lazer e o jogo, pelo abandono das relações sociais que se pautam exclusivamente na produção e consumo de bens descartáveis e inúteis. Na pauta reivindicada pelo autor, trata-se da reconquista do tempo pessoal, entendido como tempo qualitativo, lento, que cultiva a contemplação e minimiza o consumo e a degradação que lhe é inerente. Em outras palavras, valoriza novos processos de subjetivação.

É preciso haver uma política do tempo que inclua a reorganização do ambiente de vida, a política cultural, a formação e a educação, e que refunde os serviços sociais e os equipamentos 
coletivos de tal modo que neles haja mais espaço para as atividades autogeridas, de ajuda mútua, de cooperação e de autoprodução voluntárias. (GORZ apud LATOUCHE, 2009, p. 122).

Há uma política do tempo que pode possibilitar o resgate da dignidade e a viabilidade de uma perspectiva de vida que não represente mais apenas uma saída de emergência, ou conformidade com o pequeno espaço que se impõe: "Aqui tá virando cidade, a gente tá perdendo espaço. A cidade tá tomando frente.". Esta frase foi enunciada por Ademir, um adulto jovem entrevistado no início de nossos trabalhos com os carroceiros que trafegam entre o campo e a cidade de Seropédica. O pai de Ademir é um dos que utilizam cotidianamente a carroça para buscar as sobras de alimentos em restaurantes e escolas da cidade, para dar de comer aos porcos. Fora esse uso, ele também presta ocasionais serviços de frete, principalmente mudanças e transporte de materiais de construção.

O enunciado do jovem carroceiro nos remete à interpretação de que, ao tomar frente, a cidade rompe, fere, violenta modos de vida historicamente construídos, com forte carga simbólica e modos próprios de expressão, e assim oculta as subjetividades criadoras, produzindo uma indesejável condição de marginalidade social.

A insistência do uso de transporte com tração animal no município de Seropédica corresponde a duas perspectivas: por um lado há uma situação de precariedade do ponto de vista econômico, de exclusão sistemática dos mercados de trabalho, que obriga a que certos atores sociais criem situações excepcionais para se relacionarem com o circuito de urbanização - assim, fazer fretes, carrear lavagem para os animais, carregar entulhos, são formas de sobrevivência que se configuram perfeitamente no que tem sido chamado de "saídas de emergência" (CABANES; GEORGES, 2011). Por outro lado, há nestas invenções ou recriações a permanência de gostos e emoções ligadas à vida rural, com o sentido e devido valor de resistência cultural.

Os carroceiros podem adquirir certo protagonismo social, saindo das margens, se as políticas públicas assimilarem a perspectiva da rurbanização, considerando, portanto, a integração dos espaços sociais. Nesse caminho há apenas que se alertar, para finalizar, que a ultrapassagem sugerida pela noção de rurbanidade, não autoriza a adoção de estratégias de investimentos maciços de corte tecnológico em escala monumental, com implicações ecológicas, tanto quanto não legitima a adoção de nostalgias românticas ligadas a arcaísmos rurais.

Trata-se, outrossim, de pensar novas e fecundas composições, reconhecendo a expressão do hibridismo, nem sempre emancipador mas, em vários casos, expressão de resistências e inventividades, sobretudo em cotidianos em que a luta pela (sobre)vivência tem contornos frequentemente dramáticos. Trata-se também de entender os indivíduos como seres de projeto, que recorrem ao repertório de suas memórias, forjadas em suas trajetórias de vida, para exercitarem alguma margem de autonomia, artimanha e criatividade no enfrentamento de suas atuais condições e situações de vida. Nessa dinâmica, podem inclusive criar ações e espaços de resistência, tensionando relações de poder estabelecidas.

\section{REFERÊNCIAS}

CABANES, R.; GEORGES, I. Perspectivas. In: RIZEK, C. S. (Org.) Saídas de emergência: ganhar/perder a vida na periferia de São Paulo. São Paulo: Boitempo, 2011. 480p. (Coleção Estado de Sítio).

CIMADEVILLA, G. Las transformaciones del mapa cultural. In: CIMADEVILLA, G. (Org). Comunicación, tecnologia y desarrollo - discusiones y perspectivas desde el sur. Rio Cuarto: Universidad Nacional de Rio Cuarto, 2002. 
CIMADEVILLA, G.; CARNIGLIA, E. (Coord.). Relatos sobre la rurbanidad. Rio Cuarto: Universidad Nacional de Rio Cuarto, 2010.

CRUZ SOUZA, F.; MONTEIRO, R. C. Estúdio de la imagen del médio rural entre sus habitantes y possibles relaciones com los flujos migratórios. In: BENAL, A.; JIMÉNEZ, M.; ELIAS, P. (Org.). Aplicaciones en Psicología Social. Madrid: Universidad de Valencia, 2000. 179p.

ERICEIRA, R. C. S. et al. Rememorações de idosos sobre transformações ambientais em Seropédica: uma análise psicossocial. Memorandum, Belo Horizonte, v. 25, p. 112-126, 2013.

FREYRE, G. Rurbanização: que é? Recife: Ed. Massangana/Fundação Joaquim Nabuco, 1982.

FROEHLICH, J. M. Gilberto Freyre, a história ambiental e a 'rurbanização'. História Ciências Saúde Manguinhos, Rio de Janeiro, v. 7, n. 2, p. 283-303, 2000.

. Rural e natureza: a construção social do rural contemporâneo na região central do Rio Grande do Sul. 2002. 195f. Tese (Doutorado em Desenvolvimento, Agricultura e Sociedade) - Universidade Federal Rural do Rio de Janeiro, Rio de Janeiro, 2002.

FROEHLICH, J. M.; DIESEL, V. (Org.). Desenvolvimento rural: tendências e debates contemporâneos. 2. ed. Ijuí: Edunijuí, 2009.

FROEHLICH, J. M.; BRAIDA, C. Antinomias pós-modernas sobre a natureza. História Ciências Saúde Manguinhos, Rio de Janeiro, v. 17, n. 3, p. 627-641, 2010.

LATOUCHE, S. Pequeno tratado do decrescimento sereno. São Paulo: Martins Fontes, 2009.

LEFEBVRE, H. A cidade do capital. Rio de Janeiro: DP\&A, 1999.

MAGNANI, J. De perto e de dentro: notas para uma etnografia urbana. Revista Brasileira de Ciências Sociais, São Paulo, v. 17, n. 49, p. 11-29, 2002.

MONTEIRO, R. C. Novas ruralidades e políticas públicas: proposições para um debate. In: FROEHLICH, J. M.; DIESEL, V. (Org.). Desenvolvimento rural: tendências e debates contemporâneos. 2. ed. Ijuí: Edunijuí, 2009.

OLIVEIRA, R. C. O trabalho do antropólogo. São Paulo: UNESP, 2000.

SANTOS, M. A natureza do espaço - técnica e tempo: razão e emoção. São Paulo: HUCITEC, 1996.

. O tempo nas cidades. Ciência e cultura - Sociedade Brasileira para o Progresso da Ciência, São Paulo, v. 54, n. 2, 2002.

VIEGAS, L. Reflexões sobre a pesquisa etnográfica em Psicologia e Educação. Diálogos Possíveis. Salvador, UFBA, n. 1, p. 53-60, 2007.

\section{Sobre os autores:}

José Marcos Froehlich: Professor Associado do Departamento e do Programa de Pós-Graduação em Extensão Rural; Pós-Doutor em Antropologia Social; Doutor em Ciências Sociais; Mestre em Sociologia. Universidade Federal de Santa Maria. E-mail: jmarcos.froehlich@gmail.com

Rosa Cristina Monteiro: Professora Associada do Departamento de Psicologia e do PPG em Educação Agrícola da UFRRJ; Doutora em Ciências Sociais. Universidade Federal Rural do Rio de Janeiro. E-mail: rosacristina.monteiro@gmail.com

Ronald Clay dos Santos Ericeira: Professor Adjunto do Departamento e do PPG em Psicologia da UFRRJ; Doutor em Psicologia Social. Universidade Federal Rural do Rio de Janeiro. E-mail: ronaldericeira@yahoo.com.br 
